\title{
Premorbid risk markers for chronic fatigue syndrome in the 1958 British birth cohort
}

Charlotte Clark, Laura Goodwin, Stephen A. Stansfeld, Matthew Hotopf and Peter D. White

\section{Background}

Little is known about the aetiology of chronic fatigue syndrome/myalgic encephalomyelitis (CFS/ME); prospective studies suggest a role for premorbid mood disorder

\section{Aims}

To examine childhood and early adult adversity, ill health and physical activity as premorbid risk markers for CFS/ME by 42 years, taking psychopathology into account.

\section{Method}

Data were from the 1958 British birth cohort, a prospective study from birth to 42 years $(n=11419)$. The outcomes were self-reported CFS/ME $(n=127)$ and operationally defined CFS-like illness $(n=241)$ at 42 years

\section{Results}

Adjusting for psychopathology, parental physical abuse (odds ratio $(\mathrm{OR})=2.10,95 \% \mathrm{Cl} 1.16-3.81$ ), childhood gastrointestinal symptoms $(\mathrm{OR}=1.58,95 \% \mathrm{Cl} 1.00-2.50)$ and parental reports of many colds $(\mathrm{OR}=1.65,95 \% \mathrm{Cl} 1.09-2.50)$ were independently associated with self-reported CFS/ME. Female gender and premorbid psychopathology were the only risk markers for CFS-like illness, independent of comorbid psychopathology.

\section{Conclusions}

This confirms the importance of premorbid psychopathology in the aetiological pathways of CFS/ME, and replicates retrospective findings that childhood adversity may play a role in a minority.

\section{Declaration of interest}

P.D.W. has done consultancy work for the Department for Work and Pensions and a re-insurance company.
Chronic fatigue syndrome, also known as myalgic encephalomyelitis (CFS/ME), is a disabling illness, characterised by prolonged fatigue lasting over 6 months, with accompanying symptoms such as muscle/joint pain, poor concentration and disturbed sleep. ${ }^{1}$ The population prevalence of CFS/ME is between 0.2 and $2.6 \%{ }^{2}$ and little is known about the aetiology of the illness, making prevention and treatment challenging. ${ }^{2}$ Aetiological studies are largely limited to cross-sectional matched case-control studies of small samples. In terms of predisposing risk markers for $\mathrm{CFS} / \mathrm{ME},{ }^{3,4}$ these studies suggest some evidence for retrospectively self-reported childhood adversity, such as sexual and physical abuse, and neglect, ${ }^{5,6}$ as well as for personality factors such as emotional stability ${ }^{7}$ and perfectionism, ${ }^{8}$ and physical inactivity and overactivity. ${ }^{9,10}$ Precipitating factors include infections such as viral meningitis or glandular fever, as well as acute stress or life events. ${ }^{11}$ Large-scale prospective population studies remain a research priority ${ }^{11}$ and analyses of the 1946 and 1958 British birth cohorts provide prospective evidence for premorbid adulthood mood disorders being a predisposing risk marker for CFS/ME. ${ }^{3,4}$ However, this association was not demonstrated in analyses of the 1970 cohort examining childhood psychopathology. ${ }^{9}$ These cohorts also provide differing evidence for other risk markers including childhood and adulthood activity levels, and childhood illnesses. $^{3,4,9,10}$ Risk markers for CFS/ME have often been determined by studies that do not take other known risk markers into account. ${ }^{11}$ A recent systematic review of multivariable aetiological studies identified only a few studies and concluded that most findings have not been replicated. ${ }^{11}$ Further, many proposed risk markers for CFS/ME such as childhood psychopathology or adversity are also risk markers for adulthood psychopathology, which is often comorbid with CFS/ME. Given the increasing evidence for adulthood premorbid psychopathology as a risk factor for CFS/ME, the examination of other risk markers needs to take comorbid psychopathology into account. Also, the extent to which risk markers are confounded by other risk markers is unknown. This paper examines life-course risk markers for CFS/ME at 42 years in the prospective 1958 British birth cohort. First, specific hypotheses relating to individual childhood and adulthood risk markers were tested. The hypothesised risk markers were childhood adversity; childhood and adulthood physical overactivity; childhood physical inactivity; low and high body mass index (BMI) in childhood; and chronic childhood illnesses. Childhood BMI was hypothesised to mediate the risk of inactivity but not overactivity in childhood and adulthood. Second, multivariable models of risk markers were tested, taking into account coexisting risk markers and both premorbid and comorbid psychopathology, in order to identify independent risk markers for CFS/ME. This paper studies both self-reported and operationalised CFS, something not previously examined in birth cohort studies. Ethical approval for the survey was obtained from the North Thames Multi-Centre Research Ethics Committee.

\section{Method}

\section{Sample}

Data were from the National Child Development Study (NCDS); a longitudinal birth cohort of $98 \%$ of births in England, Scotland and Wales during 1 week in March $1958(n=18558)$. Data were from parents and schools at 7,11 and 16 years of age and from participant interviews at 7, 11, 16, 23, 33 and 42 years. Analyses are based on 11419 cohort members who participated at 42 years (71\% of the invited sample). ${ }^{12}$

\section{Measures}

CFS/ME and CFS-like illness

Self-reported diagnoses of CFS/ME ('Have you ever had CFS/ ME?') were available at 42 years, along with the age at onset. 
CFS-like illness was defined independently of self-reported diagnosis at 42 years. The criteria used were broadly equivalent to the Centers for Disease Control and Prevention (CDC) criteria for CFS, ${ }^{1}$ requiring a self-report of 'feeling tired most of the time', in addition to $\geqslant 4$ from the following symptoms from the Malaise Inventory: ${ }^{13}$ 'bad headaches', 'difficulty falling asleep/ staying asleep', 'backache', 'rheumatism/fibrositis' and 'being unable to concentrate' from the (General Health Questionnaire) GHQ-12. ${ }^{14}$ The Malaise Inventory and the GHQ-12 assess these symptoms in the weeks prior to the interview. ${ }^{14,15}$ For the comparison group, participants who met the CDC exclusion criteria for CFS/ME (self-reported anorexia/bulimia at 42 years, ulcerative colitis, any cancer, Crohn's disease, alcohol/substance misuse, BMI $>40)$ were excluded $(n=2157){ }^{1}$

\section{Adulthood psychopathology}

Psychopathology at 23, 33 and 42 years was measured using the Malaise Inventory, ${ }^{13}$ which assesses self-reports of 24 psychological and somatic symptoms. The inventory focuses on symptoms but has demonstrated validity to discriminate those with recent psychiatric diagnoses and contact with services. ${ }^{15} \mathrm{~A}$ 17-item adapted version of the inventory was used, after excluding 7 somatic symptoms found with CFS/ME, to avoid tautological defining characteristics of CFS/ME such as fatigue being used to predict CFS/ME. On the complete inventory $\geqslant 7$ indicates a high level of distress, representing $29 \%$ of the total score of $24,{ }^{15}$ therefore an equivalent cut-off of $\geqslant 5$ representing $29 \%$ of the revised total score of 17 was used.

\section{Childhood adversity}

Prospective measures of childhood adversity were available at 7, 11 and 16 years, including doctor-reported neglected/underfed appearance, along with parental reports of being in care and maternal and paternal absence. ${ }^{16}$ Parental divorce was reported by parents in childhood and by the cohort-member at 33 years. Parental physical or sexual abuse were self-reported retrospectively at 45 years. Cumulative adversity counted the number of adversities reported from 7 to 16 years $(0,1,2,3+) .{ }^{16}$

\section{Childhood and adulthood physical activity}

Childhood measures included teacher reports of the child's ability at sport at 16 years (below average/average/above average); parental reports of the activity levels of the child at 7 years (inactive/normally active/overactive) and the frequency of playing sport at 11 years (hardly ever/sometimes/most days); and cohortmember report of frequency of playing outdoor sports in their leisure time at 16 years (hardly ever/sometimes/often). For these measures normally active, sometimes, or average was the reference group to compare under- and overactivity as a risk for CFS/ME. ${ }^{17}$

At 23 years frequency of sports/keep fit activities in an average month was self-reported categorised, as ' 2 times in the last 4 weeks/2 times a week' (reference group), 'never/once in the last month', and ' $3-4 />5$ times a week'. A similar self-reported measure was derived at 33 years, categorised as 'once a week/ 2-3 times a month/2-3 times a week' (reference group), 'never/less often', and ' $4+$ times a week'. Self-reported physical activity at work at 33 years was categorised as 'no activity at work', 'some activity' (reference group), and 'high activity'.

\section{Body mass index}

Body mass index was available from 7 to 33 years, from height and weight measurements in childhood and self-reports in adulthood.
In adulthood, $<18.5$ was underweight, 18.5 to $<25$ normal, 25 to $<30$ overweight, and $\geqslant 30$ obese. In childhood, overweight and obesity were based on guidelines derived using international data: ${ }^{18}$ no definition of underweight is available for children.

\section{Childhood illness}

Childhood illnesses were reported by parents, usually the mother. Dichotomous measures were derived that indicated the following illnesses during childhood (defined as 7-11 years) or adolescence (16 years): any somatic symptoms (for example bad turns, sleeping difficulties), any gastrointestinal symptoms (such as tummy upsets, stomach aches, feeling sick), any gastrointestinal diagnosis (for example gastroenteritis, hernia, abnormal alimentary system), chronic illness (such as diabetes, epilepsy), atopy, three or more throat infections in the previous year, many colds, and headaches/migraines. The number of infectious illnesses (such as chicken pox, measles) at 7 or 11 years and 16 years and absence from school because of illness at 11 years and 16 years were available. Illnesses were defined as either childhood (7 or 11 years) or adolescent (16 years) to examine critical periods for effects on CFS/ME: 7 and 11 year outcomes were combined as the findings did not differ. Dichotomous measures of mother or father's psychiatric illness were derived, along with a measure of any physical or psychological illness in the family.

\section{Sample attrition and multiple imputation}

Follow-up in childhood was good with $89 \%$ of the original sample participating at 7 years, $88 \%$ at 11 years and $84 \%$ at 16 years. ${ }^{12}$ In adulthood $72 \%$ participated at 23 years, $65 \%$ at 33 years and $66 \%$ at 42 years. ${ }^{12}$ Multiple imputation using regression addressed the issue of missing data on the analyses, ${ }^{19}$ based on the assumption that data were missing at random ${ }^{20}$ using the ICE programme in STATA (Version 10) for Windows. All variables reported in this paper were included in the imputation equations. ${ }^{21}$ Gender, socioeconomic position at 7 and 42 , and qualifications at 33 that predict attrition were also included. ${ }^{20}$ Missing data on the independent variables ranged from $<1$ to $25 \%$ except for neglected appearance at 7 or 11 years $(38 \%)$, maternal absence at 16 years $(26 \%)$, school absence at 16 years $(28 \%)$, sport at 16 years $(28 \%)$ and physical activity in job at 33 years $(30 \%)$. All participants, except 1120 who had died during the study, were included in the imputation: analyses are restricted to those who participated at 42 years. Five cycles of the imputation were run and analyses indicated that the measures were stable across the imputations. Parameter estimates from the five imputations were estimated using the MIM function in STATA. Interaction terms were not included in the imputation equation as there were no significant interactions between the risk markers and gender or socioeconomic factors. The odds ratios presented use imputed data, but analyses using the imputed and non-imputed data showed similar patterns of results.

\section{Statistical analysis}

First, the prevalence of self-reported CFS/ME and CFS-like illness were established. Second, logistic regression analyses examined the associations between each individual risk marker (childhood adversity, childhood illness, physical activity; BMI) and each outcome, adjusted for gender, which was a covariate for CFS/ ME: gender $\times$ risk marker interactions were not significant. Socioeconomic factors were not covariates as they did not predict CFS/ME. Adulthood risk markers preceded onset: for example a risk marker at 23 years was assessed for those with CFS/ME onset after 24 years. Whether BMI mediated the associations between 
physical activity and CFS/ME was assessed using Sobel tests assessing the significance of the reduction in variance explained by the risk marker after adjustment for BMI. Finally, to test the hypotheses that coexisting risk markers might explain observed associations, multivariable logistic regression models were run that incorporated all of the risk markers that showed a significant association with CFS/ME or CFS-like illness, after adjustment for gender (cumulative adversity was excluded as it was derived from the individual adversity measures). These models were then subsequently adjusted for premorbid adulthood psychopathology at 23 and 33 years; and concurrent adulthood psychopathology at 42 years.

\section{Results}

The prevalence of self-reported CFS/ME in this cohort was $1.0 \%$ (95\% CI 1.0-1.2) ( $n=127: 75$ female, 52 male), with a median age at onset of 34 years (mean 32.5, s.d. $=6.9$ ). CFS-like illness was reported by $2.0 \%$ (95\% CI 2.0-2.2) ( $n=241: 167$ female, 74 male). Female gender was significantly associated with CFS/ME (odds ratio $(\mathrm{OR})=1.50,95 \% \mathrm{CI} 1.04-2.14, P=0.029)$ and with CFS-like illness $(\mathrm{OR}=2.36,95 \% \mathrm{CI} 1.79-3.11, P=0.001)$.

\section{Childhood adversity}

Table 1 shows that self-reported parental physical abuse, sexual abuse, and reports of three or more childhood adversities were associated with a 2.4-3.0-fold increase in odds for CFS/ME. Illness in the household, neglected appearance, maternal absence, paternal absence, being in care, parental divorce, physical abuse, sexual abuse and cumulative adversity were all significantly associated with increased odds for CFS-like illness (ORs ranged from 1.6 to 3.7$)$.

\section{Childhood illness}

There were few significant associations between the childhood illnesses and CFS/ME or CFS-like illness (online Table DS1). Gastrointestinal symptoms at 7 or 11 years, chronic illness at 7 or 11 years, and many colds at 7 or 11 years significantly increased the odds for CFS/ME (ORs ranged from 1.6 to 1.9). Absence from school for over 1 month at both 11 and 16 years doubled the odds for CFS/ME. Many colds at 7 or 11 years, three or more throat infections at 16 years, headaches at 16 years, psychiatric illness in the family, and absence from school for over 1 month at 16 years all significantly increased the odds for CFS-like illness (ORs ranged from 1.4 to 2.4 ).

\section{BMI and activity levels}

Childhood BMI and activity levels were not associated with either CFS/ME or CFS-like illness (results not shown). There were no significant associations between adulthood activity levels or BMI with later CFS/ME (results not shown). Obesity at 23 and 33 years were both associated with increased odds for CFS-like illness

\begin{tabular}{|c|c|c|c|c|c|c|c|}
\hline \multirow[b]{2}{*}{ Childhood adversity (age) } & \multicolumn{3}{|c|}{ Frequencies $(n=11419)$} & \multicolumn{2}{|c|}{ CFS/ME $(n=9374)^{\mathrm{a}}$} & \multicolumn{2}{|c|}{ CFS-like illness ( $n=9368$ ) } \\
\hline & Sample, $n(\%)$ & CFS/ME, $n(\%)$ & CFS-like illness, $n(\%)$ & OR & $95 \% \mathrm{Cl}$ & OR & $95 \% \mathrm{Cl}$ \\
\hline \multicolumn{8}{|l|}{ Illness in the household (7-16) } \\
\hline No & $9122(79.9)$ & $100(78.7)$ & $171(71.0)$ & 1.00 & & 1.00 & \\
\hline Yes & $2297(20.1)$ & $27(21.3)$ & $70(29.0)$ & 1.07 & $0.67-1.71$ & $1.66^{* * *}$ & $1.23-2.22$ \\
\hline \multicolumn{8}{|c|}{ Neglected/underfed appearance (7-11) } \\
\hline No & $10368(90.8)$ & $113(89.0)$ & $204(84.6)$ & 1.00 & & 1.00 & \\
\hline Yes & $1051(9.2)$ & $14(11.0)$ & 37 (15.4) & 1.27 & $0.51-3.16$ & $2.07 * *$ & $1.24-3.45$ \\
\hline \multicolumn{8}{|l|}{ Maternal absence (7-16) } \\
\hline No & $10681(93.5)$ & $120(94.5)$ & $215(89.2)$ & 1.00 & & 1.00 & \\
\hline Yes & $738(6.5)$ & $7(5.5)$ & $26(10.8)$ & 0.84 & $0.18-3.84$ & $1.79 * *$ & $1.17-2.74$ \\
\hline \multicolumn{8}{|l|}{ Paternal absence (7-16) } \\
\hline No & 9805 (85.9) & $110(86.6)$ & $189(78.4)$ & 1.00 & & 1.00 & \\
\hline Yes & $1614(14.1)$ & 17 (13.4) & $52(21.6)$ & 0.96 & $0.55-1.65$ & $1.69 * *$ & $1.18-2.41$ \\
\hline \multicolumn{8}{|l|}{ In care (7-16) } \\
\hline No & $10826(94.8)$ & $115(90.6)$ & $221(91.7)$ & 1.00 & & 1.00 & \\
\hline Yes & $593(5.2)$ & $12(9.4)$ & $20(8.3)$ & 2.04 & $0.93-4.49$ & $1.80 *$ & $1.06-3.06$ \\
\hline \multicolumn{8}{|l|}{ Divorce of parents } \\
\hline No & $10154(88.9)$ & $111(87.4)$ & $198(82.2)$ & 1.00 & & 1.00 & \\
\hline Yes & 1265 (11.1) & $16(12.6)$ & $43(17.8)$ & 1.18 & $0.66-2.10$ & $1.73^{* *}$ & $1.22-2.45$ \\
\hline \multicolumn{8}{|l|}{ Parental physical abuse } \\
\hline No & 10649 (93.3) & $106(83.5)$ & $202(83.8)$ & 1.00 & & 1.00 & \\
\hline Yes & $770(6.7)$ & $21(16.5)$ & 39 (16.2) & $3.01 * * *$ & $1.73-5.24$ & $3.07 * * *$ & $2.12-4.46$ \\
\hline \multicolumn{8}{|l|}{ Parental sexual abuse } \\
\hline No & $11157(97.7)$ & 119 (93.7) & $225(93.4)$ & 1.00 & & 1.00 & \\
\hline Yes & $262(2.3)$ & $8(6.3)$ & $16(6.6)$ & $3.02 * * *$ & $1.42-6.39$ & $2.87^{\star \star}$ & $1.50-5.52$ \\
\hline \multicolumn{8}{|l|}{ Cumulative adversity scale } \\
\hline 0 & $7754(67.9)$ & $74(58.3)$ & $122(50.6)$ & 1.00 & & 1.00 & \\
\hline 1 & $2582(22.6)$ & $32(25.2)$ & $65(27.0)$ & 1.36 & $0.66-2.81$ & $1.69 * *$ & $1.18-2.40$ \\
\hline 2 & $697(6.1)$ & $13(10.2)$ & $33(13.7)$ & 2.04 & $0.86-4.81$ & $3.26 * * *$ & $2.14-4.96$ \\
\hline $3+$ & $386(3.4)$ & $8(6.3)$ & $21(8.7)$ & $2.47 *$ & $1.09-5.61$ & $3.71 * * *$ & $2.03-6.81$ \\
\hline
\end{tabular}


$(\mathrm{OR}=2.41,95 \%$ CI $1.10-5.28 ; \mathrm{OR}=1.92,95 \% \mathrm{C} 11.32-2.80)$, as was being overweight at 23 years $(\mathrm{OR}=1.48,95 \% 1.02-2.14)$. Leisure-time inactivity at both 23 and 33 years moderately increased the odds for CFS-like illness $(\mathrm{OR}=2.31,95 \%$ CI 1.58-3.36; $\mathrm{OR}=1.83,95 \%$ CI 1.34-2.49, respectively). Adjusting the significant physical activity findings for concurrent BMI did not alter the findings.

\section{Adulthood psychopathology}

Adulthood psychopathology was strongly associated with CFS/ME (23 year OR $=1.89,95 \%$ CI $1.06-3.21 ; 33$ years $\mathrm{OR}=2.81,95 \% \mathrm{CI}$ $1.28-6.18$; 42 years $\mathrm{OR}=5.44,95 \% \mathrm{CI}=3.10-9.56)$ and CFS-like illness $(23$ years $\mathrm{OR}=5.97,95 \%$ CI $4.37-8.15 ; 33$ years $\mathrm{OR}=10.89,95 \%$ CI $7.84-15.12 ; 42$ years $\mathrm{OR}=21.7,95 \%$ $\mathrm{CI}=16.08-29.34)$.

\section{Multivariable risk markers}

Prior to adjustment for psychopathology, parental physical abuse in childhood was associated with a 2.6 -fold increase in odds for CFS/ME; gastrointestinal symptoms at 7 or 11 years and reporting many colds at 7 and 11 years were associated with a 1.6- and 1.7-fold increase in odds, respectively (Table 2). These associations attenuated slightly with adjustment for premorbid (psychopathology at 23 and 33 years) and comorbid psychopathology (psychopathology at 42 years), but remained significant. Psychopathology at 33 was associated with a 2.2-fold increase in odds for CFS/ME but this association was not significant after adjustment for comorbid psychopathology at 42 years, which was associated with a 3.7-fold increase in odds for CFS/ME.

For CFS-like illness, being female was associated with a 2-fold increase in odds; parental physical abuse in childhood with a 2.4-fold increase in odds; leisure-time inactivity at 23 years with a 1.9-fold increase in odds, and leisure-time inactivity at 33 years with a 1.5 -fold increase in odds (Table 3 ). These associations attenuated with adjustment for premorbid (psychopathology at 23 and 33 years) and comorbid psychopathology (psychopathology at 42 years), remaining significant for being female, becoming borderline significant for leisure-time inactivity at 23 years $(P=0.08)$ and non-significant for leisure-time inactivity at 33 years. Parental physical abuse became non- significant after adjustment for comorbid psychopathology at 42 years. Premorbid psychopathology at 33 was still associated, even after adjusting for concurrent psychopathology at 42 years.

\section{Discussion}

\section{Summary of findings}

Hypothesis testing of the individual risk markers identified similar premorbid risk markers for self-reported CFS/ME and CFS-like illness, suggesting aetiological roles for childhood adversity, adulthood physical inactivity, adulthood BMI and some childhood illnesses but not for childhood BMI or activity levels. Multivariable models, adjusted for premorbid and comorbid psychopathology identified parental physical abuse, childhood gastrointestinal symptoms and reporting many colds as independent risk markers for self-reported CFS/ME. Only female gender and adult premorbid psychopathology were risk markers for CFS-like illness after adjustment for comorbid psychopathology. Parental physical abuse and early adulthood psychopathology were premorbid risks for both CFS/ME and CFS-like illness, strengthening the evidence for their aetiological role, while also finding this association to be partially confounded by comorbid psychopathology. Overall, the statistically significant risk markers affected only the minority of individuals, however defined, so that, for example, only $16 \%$ of individuals reported

\begin{tabular}{|c|c|c|c|c|c|c|}
\hline \multirow[b]{2}{*}{ Risk/protective marker } & \multicolumn{2}{|c|}{$\begin{array}{c}\text { CFS/ME, model adjusted for } \\
\text { coexisting risk markers }(n=9374)\end{array}$} & \multicolumn{2}{|c|}{$\begin{array}{l}\text { CFS/ME, model adjusted for } \\
\text { coexisting risk markers and } \\
\text { premorbid psychopathology at } \\
23 \text { and } 33 \text { years }(n=9374)\end{array}$} & \multicolumn{2}{|c|}{$\begin{array}{c}\text { CFS/ME: model adjusted for } \\
\text { coexisting risk markers, premorbid } \\
\text { psychopathology at } 23 \text { and } 33 \text { years, } \\
\text { and comorbid psychopathology } \\
\text { at } 42 \text { years }(n=9374)\end{array}$} \\
\hline & OR & $95 \% \mathrm{Cl}$ & OR & $95 \% \mathrm{Cl}$ & OR & $95 \% \mathrm{Cl}$ \\
\hline Female & 1.39 & $0.96-2.00$ & 1.31 & $0.89-1.91$ & 1.25 & $0.86-1.83$ \\
\hline Parental physical abuse & $2.60 * * *$ & $1.46-4.64$ & $2.39 * *$ & $1.30-4.38$ & $2.10^{*}$ & $1.16-3.81$ \\
\hline Parental sexual abuse & 1.86 & $0.84-4.12$ & 1.66 & $0.75-3.69$ & 1.58 & $0.71-3.53$ \\
\hline $\begin{array}{l}\text { Gastrointestinal symptoms: } 1 \\
\text { or more symptom at } 7 \text { or } 11 \text { years }\end{array}$ & $1.58^{*}$ & $1.00-2.48$ & 1.55 & $0.99-2.45$ & $1.58^{*}$ & $1.00-2.50$ \\
\hline $\begin{array}{l}\text { Chronic illness: } 1 \text { or more illness } \\
\text { at } 7 \text { or } 11 \text { years }\end{array}$ & 1.46 & $0.96-2.21$ & 1.44 & $0.95-2.19$ & 1.43 & $0.94-2.19$ \\
\hline Many colds at 7 or 11 & $1.69 *$ & $1.11-2.56$ & $1.66^{*}$ & $1.09-2.51$ & $1.65^{*}$ & $1.09-2.50$ \\
\hline $\begin{array}{l}\text { School absence at } 11 \text { years } \\
\text { Less than } 1 \text { week } \\
1 \text { week to } 1 \text { month } \\
\text { Over } 1 \text { month }\end{array}$ & $\begin{array}{l}1.00 \\
1.03 \\
1.73\end{array}$ & $\begin{array}{l}0.65-1.61 \\
0.90-3.22\end{array}$ & $\begin{array}{l}1.00 \\
1.02 \\
1.70\end{array}$ & $\begin{array}{l}0.65-1.60 \\
0.88-3.25\end{array}$ & $\begin{array}{l}1.00 \\
0.99 \\
1.62\end{array}$ & $\begin{array}{l}0.63-1.57 \\
0.84-3.13\end{array}$ \\
\hline $\begin{array}{l}\text { School absence at } 16 \text { years } \\
\text { Less than } 1 \text { week } \\
1 \text { week to } 1 \text { month } \\
\text { Over } 1 \text { month }\end{array}$ & $\begin{array}{l}1.00 \\
1.38 \\
1.57\end{array}$ & $\begin{array}{l}1.00 \\
0.92-2.08 \\
0.85-2.91\end{array}$ & $\begin{array}{l}1.00 \\
1.37 \\
1.48\end{array}$ & $\begin{array}{l}1.00 \\
0.90-2.06 \\
0.80-2.75\end{array}$ & $\begin{array}{l}1.00 \\
1.34 \\
1.43\end{array}$ & $\begin{array}{l}1.00 \\
0.89-2.03 \\
0.77-2.67\end{array}$ \\
\hline Psychopathology at 23 years & & & 1.05 & $0.57-1.94$ & 0.76 & $0.42-1.40$ \\
\hline Psychopathology at 33 years & & & $2.27 * *$ & $1.28-4.01$ & 1.40 & $0.76-2.57$ \\
\hline Psychopathology at 42 years & & & & & $3.76 * * *$ & $2.44-5.79$ \\
\hline
\end{tabular}


Table 3 Multivariable odds ratios between risk markers and chronic fatigue syndrome (CFS)-like illness by 42 years

\begin{tabular}{|c|c|c|c|c|c|c|}
\hline \multirow[b]{2}{*}{ Risk/protective marker } & \multicolumn{2}{|c|}{$\begin{array}{l}\text { CFS-like illness: model } \\
\text { adjusted for coexisting } \\
\text { risk markers }(n=9368)\end{array}$} & \multicolumn{2}{|c|}{$\begin{array}{l}\text { CFS-like illness: model adjusted for } \\
\text { coexisting risk markers and premorbid } \\
\text { psychopathology at } 23 \text { and } 33 \text { years } \\
(n=9368)\end{array}$} & \multicolumn{2}{|c|}{$\begin{array}{l}\text { CFS-like illness: model adjusted for } \\
\text { coexisting risk markers, premorbid } \\
\text { psychopathology at } 23 \text { and } 33 \text { years, } \\
\text { and comorbid psychopathology } \\
\text { at } 42 \text { years }(n=9368)\end{array}$} \\
\hline & OR & $95 \% \mathrm{Cl}$ & OR & $95 \% \mathrm{Cl}$ & OR & $95 \% \mathrm{Cl}$ \\
\hline Female & $2.05^{\star \star *}$ & $1.52-2.77$ & $1.62^{\star *}$ & $1.17-2.24$ & $1.59 * *$ & $1.14-2.21$ \\
\hline Illness in the household (7-16) & 1.32 & $0.94-1.84$ & 1.20 & $0.84-1.72$ & 1.15 & $0.79-1.65$ \\
\hline Neglected/underfed appearance (7-11) & 1.49 & $0.81-2.71$ & 1.38 & $0.77-2.47$ & 1.34 & $0.76-2.39$ \\
\hline Maternal absence $(7-16)$ & 1.43 & $0.89-2.30$ & 1.27 & $0.77-2.07$ & 1.39 & $0.83-2.33$ \\
\hline Paternal absence (7-16) & 1.23 & $0.74-2.03$ & 1.22 & $0.72-2.08$ & 1.14 & $0.64-2.02$ \\
\hline In care (7-16) & 1.05 & $0.54-2.05$ & 0.76 & $0.33-1.76$ & 0.76 & $0.34-1.70$ \\
\hline Divorce of parents & 0.99 & $0.60-1.61$ & 0.86 & $0.50-1.47$ & 0.88 & $0.51-1.53$ \\
\hline Parental physical abuse & $2.44^{* \star *}$ & $1.60-3.70$ & $1.94^{*}$ & $1.17-3.20$ & 1.56 & $0.96-2.52$ \\
\hline Parental sexual abuse & 1.48 & $0.69-3.17$ & 1.16 & $0.55-2.42$ & 1.09 & $0.48-2.46$ \\
\hline Many colds at 7 or 11 years & 1.19 & $0.81-1.74$ & 1.07 & $0.69-1.64$ & 1.07 & $0.70-1.64$ \\
\hline $\begin{array}{l}\text { More than } 3 \text { throat infections in previous } \\
\text { year at } 16 \text { years }\end{array}$ & 1.07 & $0.69-1.66$ & 1.08 & $0.69-1.69$ & 1.05 & $0.65-1.70$ \\
\hline Headaches or migraine at 16 years & 1.20 & $0.83-1.75$ & 1.02 & $0.69-1.51$ & 0.88 & $0.59-1.32$ \\
\hline \multicolumn{7}{|l|}{ School absence at 16 years } \\
\hline Less than 1 week & 1.00 & & 1.00 & & 1.00 & \\
\hline 1 week to 1 month & 1.28 & $0.72-2.27$ & 1.21 & $0.68-2.15$ & 1.20 & $0.68-2.11$ \\
\hline Over 1 month & 1.69 & $0.95-3.02$ & 1.37 & $0.73-2.55$ & 1.33 & $0.70-2.52$ \\
\hline Any report of family psychiatric illness & 1.18 & $0.65-2.11$ & 1.09 & $0.56-2.11$ & 1.25 & $0.61-2.54$ \\
\hline \multicolumn{7}{|l|}{ BMI at 23 years } \\
\hline Underweight & 0.71 & $0.34-1.48$ & 0.67 & $0.31-1.44$ & 0.53 & $0.24-1.16$ \\
\hline Overweight & 1.17 & $0.75-1.84$ & 1.04 & $0.65-1.67$ & 1.04 & $0.64-1.69$ \\
\hline Obese & 1.75 & $0.64-4.78$ & 1.68 & $0.60-4.75$ & 1.81 & $0.66-4.99$ \\
\hline \multicolumn{7}{|l|}{ BMI at 33 years } \\
\hline Underweight & 1.97 & $0.93-4.19$ & 1.92 & $0.84-4.38$ & 1.94 & $0.83-4.57$ \\
\hline Overweight & 1.14 & $0.81-1.61$ & 1.08 & $0.77-1.52$ & 1.14 & $0.80-1.62$ \\
\hline Obese & 1.36 & $0.76-2.43$ & 1.44 & $0.79-2.64$ & 1.53 & $0.80-2.91$ \\
\hline \multicolumn{7}{|l|}{ Leisure-time physical activity at 23 years } \\
\hline Never or once in last 4 weeks & $1.92^{\star * *}$ & $1.31-2.81$ & $1.64^{*}$ & $1.09-2.47$ & 1.47 & $0.98-0.23$ \\
\hline 3-4 times $/ 5+$ times a week & 1.14 & $0.61-2.12$ & 1.25 & $0.64-2.44$ & 1.24 & $0.64-2.42$ \\
\hline \multicolumn{7}{|l|}{ Leisure-time physical activity at 33 years } \\
\hline Never/less often & $1.51^{*}$ & $1.10-2.08$ & 1.27 & $0.90-1.78$ & 1.18 & $0.81-1.71$ \\
\hline $4+$ times a week & 1.01 & $0.71-1.45$ & 0.95 & $0.65-1.38$ & 0.91 & $0.62-1.35$ \\
\hline Psychopathology at 23 years & & & $2.31 * * *$ & $1.61-3.31$ & 1.31 & $0.91-1.89$ \\
\hline Psychopathology at 33 years & & & $6.26^{* * *}$ & $4.37-8.96$ & $2.83^{\star \star \star}$ & $1.94-4.11$ \\
\hline Psychopathology at 42 years & & & & & $12.84^{* * *}$ & $9.08-18.17$ \\
\hline${ }^{*} P=0.05,{ }^{*} P P=0.01,{ }^{*} * * P=0.001$ & & & & & & \\
\hline
\end{tabular}

parental physical abuse. This may reflect that CFS/ME is a heterogeneous condition ${ }^{22}$ and future studies will need to define subgroups to further elucidate aetiological pathways.

\section{Premorbid psychopathology and childhood adversity}

This study confirms the importance of premorbid adulthood psychopathology in the aetiology of CFS/ME and CFS-like illness ${ }^{3}$ and demonstrates the need to take premorbid and comorbid psychopathology into account when examining risk markers for CFS/ME and CFS-like illness. The only childhood adversity that was a risk marker for CFS/ME and CFS-like illness was parental abuse confirming Heim et al's findings ${ }^{5}$ of higher reports of childhood trauma in individuals with clinically confirmed CFS/ ME compared with healthy controls. Our effect sizes were more modest than Heim et al's and only $16 \%$ of ours reported parental physical abuse. This could reflect the use of individual multipleinformant adversity measures in the current study that may lack the sensitivity of the multiple-item Childhood Trauma Scale in Heim et al's study; the lack of measures of non-parental abuse in the current study; or recall bias in studies that use retrospective uncorroborated self-reports of childhood trauma.

Childhood physical abuse is associated with a wide-range of adverse physical health outcomes in adulthood, ${ }^{23}$ suggesting that distress associated with abuse may be expressed through later physical symptoms. Childhood adversity is also associated with altered stress responses in adulthood, as evidenced by hypothalamic-pituitary-adrenal axis dysfunction, ${ }^{24}$ decreased hippocampal glucocorticoid receptor expression ${ }^{25}$ and inflammation, ${ }^{26}$ which have also been implicated in the aetiology of CFS/ME. ${ }^{27-29}$ These findings suggest that childhood adversity should be explored when people present with CFS/ME, as a history of childhood adversity is more likely to be found in CFS/ME, particularly when accompanied by concurrent psychopathology.

\section{Childhood illness}

Evidence for childhood illness as a risk marker from previous studies is equivocal. ${ }^{9,10}$ We found few associations, using more 
detailed measures of childhood illness. Risk markers included gastrointestinal symptoms, many colds, headaches/migraines, throat infections and chronic illness. However, few associations were independent of psychopathology and physiological pathways between these illnesses and CFS/ME remain unclear. Early illness experience, vicarious or the child's own, is linked with the development of medically unexplained symptoms in adulthood, ${ }^{30}$ reflecting possible pathways for CFS/ME via social learning and/or reinforcement of illness behaviour. ${ }^{31}$ The childhood illness measures may reflect the overprotectiveness of the parent, rather than illness per se. Overprotective parenting may be relevant to the formation of belief systems, such as negative schemata associated with response to illness, that may predispose to the development of CFS/ME in adulthood. ${ }^{31}$ Overall, evidence from population cohort studies regarding childhood illness as a risk marker is not strong.

\section{Childhood and adulthood activity levels and BMI}

Childhood activity levels and childhood BMI were not premorbid risk markers for CFS/ME or CFS-like illness, contrary to the findings of the 1946 and 1970 cohorts that overactivity and inactivity were risk markers. ${ }^{9,10}$ Additionally, there were no associations between early adulthood activity and BMI once co-occurring risk markers and psychopathology were taken into account. This could reflect differential associations as a result of cohort differences in rates of physical activity; ${ }^{4}$ a lack of correction for non-response bias in the 1970 and 1946 analyses; a role for childhood inactivity for earlier but not later onset of CFS/ME; the lack of power in our data to detect an effect of low BMI; unadjusted confounding by other risk markers; or chance findings associated with the lack of sensitivity of the activity questions used in cohort studies.

\section{Defining CFS/ME and CFS-like illness}

We have examined two definitions of CFS: self-reported CFS/ME and operationalised CFS-like illness. These definitions have methodological limits that may have influenced the findings. The self-reported nature of the CFS/ME measure may influence associations with the risk markers: stronger associations may be observed in samples defined using clinically assessed CFS/ME. Our CFS-like illness outcome is limited as it is derived from symptom reports in the previous few weeks, ${ }^{14,15}$ making it not directly comparable with our CFS/ME measure, which assessed having a diagnosis during adulthood. This difference could explain some of the variation in findings between the risk markers for the two outcomes. Such differences could also be explained by the lack of power for the self-reported CFS/ME analyses compared with the CFS-like illness analyses. Confidence in the associations is strengthened in those risk markers found with both definitions, such as physical abuse. Conversely, for other risk markers the effect sizes for the different outcomes do not look comparable, for example for physical activity and some childhood illness measures. Our speculations about the influence of these definitions on our findings is limited, but we note the effect of different definitions of CFS found in previous studies. ${ }^{32-34}$

\section{Strengths and limitations}

Limitations include the use of non-clinically confirmed cases of CFS/ME; retrospective reports of parental abuse, which did not capture abuse by others; adversity measures that do not assess how the individual coped with adversity; a lack of power for some analyses; and an increased chance of type 1 errors. Unmeasured genetic or other individual confounding factors could account for the associations. However, this is the first study to examine prospectively measured childhood adversity and is also the first to use imputation to compensate for missing data and attrition. Other strengths include the use of two ways to define cases, examination of a wide range of childhood illness, a good sample size with a long-follow up capturing the mean onset age for $\mathrm{CFS} / \mathrm{ME}$; and premorbidly assessed risk markers.

\section{Implications}

Many risk markers for CFS/ME and CFS-like illness were related to premorbid and comorbid psychopathology. Prospectively measured childhood adversity was not a risk marker for CFS/ ME, however defined. When measured retrospectively, parental abuse was associated in a minority but this was confounded by concurrent psychopathology for one definition of CFS/ME. No risk marker was associated with both definitions of CFS/ME in the final adjusted models, perhaps reflecting the heterogeneity of this illness. ${ }^{23}$ Female gender, childhood illness and premorbid psychopathology were risk markers for either CFS/ME or CFS-like illness, but were sometimes confounded by comorbid psychopathology. Potential pathways between risk markers, including psychopathology, and CFS/ME include childhood adversity and their consequently altered stress responses. These pathways should be the focus of further pathophysiological research, in pre-specified subgroups, to inform interventions for prevention and treatment. ${ }^{6,7,25,27,33}$

\footnotetext{
Charlotte Clark, PhD, Centre for Psychiatry, Barts \& the London School of Medicine \& Dentistry, Queen Mary University of London; Laura Goodwin, MSC, PhD, Barts \& the London School of Medicine \& Dentistry and King's College London; Stephen A. Stansfeld, MBBS, PhD, MRCP, FRCPsych, Barts \& the London School of Medicine \& Dentistry, London; Matthew Hotopf, MBBS, MSC, MRCPsych, PhD, Institute of Psychiatry, London; Peter D. White, OBE, MBBS, MD, FRCP, FRCPsych, Barts \& the London School of Medicine \& Dentistry, London, UK

Correspondence: Charlotte Clark, Centre for Psychiatry, Barts \& the London School of Medicine \& Dentistry, Queen Mary University of London, Charterhouse Square, London EC1M 6BQ, UK. Email: c.clark@qmul.ac.uk

First received 22 Jun 2010, final revision 28 Jan 2011, accepted 29 Mar 2011
}

\section{Funding}

This research was funded by the Medical Research Council (grant number G0701032). C.C. is supported by an Engineering and Physical Sciences Research Council Academic Fellowship. M.H. is supported by the NIHR Biomedical Research Centre for Mental Health at the South London and Maudsley NHS Foundation Trust and Institute of Psychiatry, Kings College London.

\section{Acknowledgements}

We are grateful to the study participants and thank Jon Johnson at the Centre for Longitudinal Studies, Institute of Education for assistance with the data.

\section{References}

1 Reeves WC, Lloyd A, Vernon SD, Klimas N, Jason LA, Bleijenberg G, et al. Identification of ambiguities in the 1994 chronic fatigue syndrome research case definition and recommendations for resolution. BMC Health Serv Res 2003; 3: 25

2 Prins JB, van der Meer JWM, Bleijenberg G. Chronic fatigue syndrome. Lancet 2006; 367: 346-55.

3 Harvey SB, Wadsworth $M$, Wessely $S$, Hotopf $M$. The relationship between prior psychiatric disorder and chronic fatigue: evidence from a national birth cohort study. Psychol Med 2008; 38: 933-40.

4 Goodwin L, White PD, Hotopf M, Stansfeld SA, Clark C. Psychopathology and physical activity as predictors of chronic fatigue syndrome in the 1958 British birth cohort: a replication study of the 1946 and 1970 birth cohorts. Ann Epidemiol 2011; 21: 243-50. 
5 Heim C, Wagner D, Maloney E, Papanicolaou DA, Solomon L, Jones JF, et al. Early adverse experience and risk for chronic fatigue syndrome - results from a population-based study. Arch Gen Psychiatry 2006; 63: 1258-66.

6 Heim C, Nater UM, Maloney E, Boneva R, Jones JF, Reeves WC. Childhood trauma and risk for chronic fatigue syndrome association with neuroendocrine dysfunction. Arch Gen Psychiatry 2009; 66: 72-80.

7 Kato K, Sullivan PF, Evengard B, Pedersen NL. Premorbid predictors of chronic fatigue. Arch Gen Psychiatry 2006; 63: 1267-72.

8 Luyten P, Houdenhove B, Cosyns N, Van den Broeck AL. Are patients with chronic fatigue syndrome perfectionistic - or were they? A case-control study. Pers Individ Dif 2006; 40: 1473-83.

9 Viner RM, Hotopf M. Childhood predictors of self reported chronic fatigue syndrome/myalgic encephalomyelitis in adults: national birth cohort study. BMJ 2004; 329: 941.

10 Harvey SB, Wadsworth M, Wessely S, Hotopf M. Etiology of chronic fatigue syndrome: testing popular hypotheses using a national birth cohort study. Psychosom Med 2008; 70: 488-95.

11 Hempel S, Chambers D, Bagnall AM, Forbes C. Risk factors for chronic fatigue syndrome/myalgic encephalomyelitis: a systematic scoping review of multiple predictor studies. Psychol Med 2008; 38: 915-26.

12 Atherton K, Fuller E, Shepherd P, Strachan DP, Power C. Loss and representativeness in a biomedical survey at age 45 years: 1958 British birth cohort. J Epidemiol Community Health 2008; 62: 216-23.

13 Rutter ML. Psycho-social disorders in childhood, and their outcome in adult life. J R Coll Physicians Lond 1970; 4: 211-8.

14 Goldberg DP, Gater R, Sartorius N, Ustun TB, Piccinelli M, Gureje O, et al. The validity of two versions of the GHQ in the WHO study of mental illness in general health care. Psychol Med 1997; 27: 191-7.

15 Rodgers B, Pickles A, Power C, Collishaw S, Maughan B. Validity of the Malaise Inventory in general population samples. Soc Psychiatry Psychiatr Epidemiol 1999; 34: 333-41.

16 Clark C, Caldwell T, Power C, Stansfeld SA. Does the influence of childhood adversity on psychopathology persist across the lifecourse? A 45 year prospective epidemiologic study. Ann Epidemiol 2010; 20: 385-94.

17 Booth FW, Lees SJ. Physically active subjects should be the control group. Med Sci Sports Exerc 2006; 38: 405-6.

18 Cole TJ, Bellizzi MC, Flegel KM, Dietz WH. Establishing a standard definition for child overweight and obesity worldwide: international survey. BMJ 2000 320: 1240.

19 Sterne JA, White IR, Carlin JB, Spratt M, Royston P, Kenward MG, et al. Multiple imputation for missing data in epidemiological and clinical research: potential and pitfalls. BMJ 2009; 29: 2393.
20 Hawkes $D$, Plewis I. Modelling non-response in the National Child Development Study. J R Stat Soc Ser A: Stat Soc 2006; 169: 479-91.

21 Collins LM, Schafer JL, Kam C. A comparison of inclusive and restrictive strategies in modern missing data procedures. Psychol Methods 2001; 6 : 330-51.

22 White PD. Chronic fatigue syndrome: Is it one discrete syndrome or many? Implications for the "one versus many" functional somatic syndromes debate. J Psychosom Res 2010; 68: 455-9.

23 Walker EA, Gelfand A, Katon WJ, Koss MP, Von Korff M, Bernsterin D, et al. Adult health status of women with histories of childhood abuse and neglect. Am J Med 1999; 107: 332-9.

24 Tarullo AR, Gunnar MR. Child maltreatment and the developing HPA axis. Horm Behav 2006; 50: 632-9.

25 McGowan PO, Sasaki A, D'Allessio AC, Dymov S, Labonte B, Szyf M, et al. Epigenetic regulation of the glucocorticoid receptor in human brain associates with childhood abuse. Nat Neurosci 2009; 12: 342-8.

26 Danese A, Pariante CM, Caspi A, Taylor A, Poulton R. Childhood maltreatment predicts adult inflammation in a life-course study. Proc Natl Acad Sci USA 2007; 104: 1319-24.

27 Rajeevan MS, Smith AK, Dimulescu I, Unger ER, Vernon SD, Heim C, et al. Glucocorticoid receptor polymorphisms and haplotypes associated with chronic fatigue syndrome. Genes Brain Behav 2007; 6: 167-76.

28 Van Den Eede F, Moorkens G, Van Houdenhove B, Cosyns P, Claes SJ. Hypothalamic-pituitary-adrenal axis function in chronic fatigue syndrome. Neuropsychobiology 2007; 55: 112-20.

29 Buchwald D, Wener MH, Pearlman T, Kith P. Markers of inflammation and immune activiation in chronic fatigue and chronic fatigue syndrome. J Rheumatol 1997; 24: 372-6.

30 Hotopf M, Mayou R, Wadsworth M, Wessely S. Childhood risk factors for adults with medically unexplained symptoms: results from a national birth cohort study. Am J Psychiatry 1999; 156: 1796-800.

31 Fisher L, Chalder T. Childhood experiences of illness and parenting in adults with chronic fatigue syndrome. J Psychosom Res 2003; 54: 439-43.

32 Hamilton WT, Gallagher AM, Thomas JM, White PD. Risk markers for both chronic fatigue and irritable bowel syndromes: a prospective case-control study in primary care. Psychol Med 2009; 39: 1913-21.

33 White PD, Thomas JM, Kangro HO, Bruce-Jones WDA, Amess J, Crawford DH, et al. Predictions and associations of fatigue syndromes and mood disorders that occur after infectious mononucleosis. Lancet 2001; 358: 1946-54.

34 Buchwald D, Herrell R, Ashton S, Belcourt M, Schmaling $K$, Sullivan $P$, et al. A twin study of chronic fatigue. Psychosom Med 2001; 63: 936-43. 